\title{
Gene therapy in cardiac surgery: Is there a role?
}

Frank W. Sellke, MD

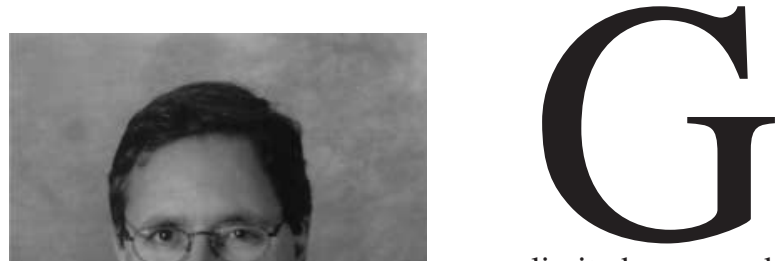

ene therapy has been billed as a method of curing most human diseases. Despite a large amount of initial enthusiasm and a vast amount of resources spent in this area, however, except in isolated cases gene-directed treatment has yielded only modest or little success. Indeed, there have been several instances in which gene therapy has resulted in adverse events and even death. Why the limited success despite initial optimism? As with most clinical issues or problems, the answer is multifactorial. With gene therapy, it is hypothesized that by the introduction of a piece of genetic material (DNA) into the host genome, the host will be able to produce enough of a protein through translation from the resultant messenger RNA to provide beneficial results. These results can be increased blood vessel growth through angiogenesis, providing a deficient vital protein involved in immune defense, or increasing the body's ability to tolerate oxidative stress in the heart after ischemia.

First, the genetic material (DNA) needs to be incorporated into the host genome. Some investigators have attempted to inject naked DNA encoding a certain protein into the tissue at various isolated areas and have reported fairly dramatic effects. I am personally somewhat skeptical that this approach will ever have much of a role in the treatment of patients. The efficiency of transfection, or the incorporation of the DNA into the genome, is extremely low with this method, and the local delivery of the DNA to such a small locus is not likely to have a widespread effect. However, other methods of gene delivery have been more successful. Second, a promoter, either native or exogenous, needs to be present to produce, or transcribe, a significant amount of messenger RNA. Messenger RNA, as opposed to DNA, is not stable and rapidly breaks down chemically through the activation of one of several degradation enzymes. This makes teleologic sense, because a genetic message in the form of messenger RNA should not hang around forever. The body needs to constantly reassess the local environment and make modifications in the cellular milieu. Third, from the messenger RNA a protein is translated. This process is also under the tight control of other structural proteins and enzymes. The protein is also subject to degradation through the activation of proteosomes and other enzymes. Fourth, the protein product then acts on the cells, usually through transmembrane receptors, and produces some signal or change the structure of the tissue. Finally, it is assumed that the protein encoded by the DNA will indeed cure the patient or at least have a positive effect. Enough of the protein needs to be around for long enough to provide a significant benefit. If any of these processes is interrupted, or if the protein actually has no effect in vivo, gene therapy will fail.

From Beth Israel Deaconess Medical Center, Harvard Medical School, Boston, Mass.

Received for publication Aug 15, 2002; accepted for publication Aug 19, 2002.

Address for reprints: Frank W. Sellke, MD, Beth Israel Deaconess Medical Center, Harvard Medical School, 110 Francis St, LMOB 2A, Boston, MA 02215 (E-mail: fsellke@caregroup.harvard.edu).

J Thorac Cardiovasc Surg 2003;125:994-7

Copyright (C) 2003 by The American Association for Thoracic Surgery

0022-5223/2003\$30.00+0

doi: $10.1067 / \mathrm{mtc} .2003 .264$

The optimal method for introduction of the DNA into the host genome has been debated and depends on the clinical situation. Injection of naked DNA strands with a syringe, as mentioned previously, is certainly the simplest method, but the efficacy of transfection is low and the DNA tends to be present for only a few days. Little protein tends to be produced. Viral vectors make the process much more efficient. The adenoviral vector is often used to move the DNA into the cell and cause its incorporation into the host genome. Expression may be extended to several weeks with adenoviral vectors. However, native circulating antibodies to the virus that are often present in the blood may neutralize the vector and markedly reduce the expression of the gene. Other viral vectors have other advantages and disadvantages relative to adenovirus. Some viral vectors, such as adenoassociated virus and lentivirus, may produce more prolonged expression. In many cases that may not be 
optimal, however, because large amounts of a protein may have toxic manifestations. There has been work done on viral vectors that may be regulated, but the applications to the clinical situation are still preliminary. Finally, the toxicities of the DNA and viral vectors are not completely understood. An unlikely but theoretically possible scenario is that a noninfective viral vector will go haywire and transmit a lethal gene to the general population.

Cell-based gene therapy is a promising new strategy that uses autologous cells transfected with a transgene of interest to express that transgene in vivo. Complex multigene vectors can be generated that allow stable, regulatable gene expression. Other nonviral methods for the introduction of DNA into the host genome, such as phospholipid liposomes, do show some promise but as yet have failed to provide a marked advantage relative to viral vectors.

Protein therapy, on the other hand, skips most of the steps involved in transfection, transcription, and translation and only assumes that the protein is effective treating the ailment and can be provided in high enough concentration and duration to be effective. The toxicity profiles of proteins are, in general, better understood than those of genetic material. However, long-term delivery is difficult with proteins and depends on the biologic half-life of the molecule in vivo. Therefore repeated delivery of sustained delivery through the use of implantable devices or repeated injections may be required for optimal therapy. ${ }^{1,2}$

Despite these limitations and potential problems, there have been a relatively large number of recent publications documenting the potential of gene therapy in cardiac surgery. I will summarize just a few of these studies. Rosengart and colleagues ${ }^{3}$ have demonstrated improved (albeit slightly) anginal symptoms after the injection of vascular endothelial growth factor DNA with the adenoviral vector through increased collateral development. Thus blood vessel formation may be increased and coronary insufficiency may be treated with gene therapy in patients who would not be considered as surgical candidates. With regard to the peripheral circulation, Baumgartner and associates ${ }^{4}$ from $\mathrm{St}$ Elizabeth's Hospital in Boston reported that the constitutive expression of vascular endothelial growth factor after intramuscular gene transfer promotes collateral vessel development in patients with limb ischemia. Although in theory this would improve peripheral blood flow, the outcome variables were vague, and a placebo was not used.

One concern is always that transfection efficacy will not be sufficient to allow the protein to be produced. However, Logeart and colleagues ${ }^{5}$ were able to show highly efficient adenovirally mediated gene transfer to cardiac myocytes after single-pass coronary delivery in rats, suggesting that gene transfer methods may be applicable to the intraoperative situation. In addition, Davidson and coworkers ${ }^{6}$ from Duke found that they could deliver transgenes to the $\beta_{2^{-}}$ adrenergic receptor in the pig through the aortic cardioplegia delivery cannula after the induction of arrest. Although protein receptor levels were increased in the myocardium, no assessment of improved ventricular function was made. In a similar study Bridges and associates ${ }^{7}$ reported that cardiac-specific transgene expression could be obtained with cardiac isolation within 15 to 30 minutes. Wang and colleagues $^{8}$ compared direct infection and perfusion as methods of delivering a transgene with an adenoviral vector. Although direct injection resulted in overall more efficient delivery, a more uniform distribution was evident with intra-aortic perfusion.

Zhu and coworkers ${ }^{9}$ demonstrated the blocking of free radical production by transfer of genes encoding catalase. This group from the University of Pennsylvania (Gardner and Sweeney) has published a large number of elegant studies showing that transfection of various genes may improve tolerance to ischemic injury in animals. Gene therapy may also show some promise in modifying vascular grafts and improving patency after coronary and peripheral bypass surgery. For example, Cable and coworkers ${ }^{10}$ at the Mayo Clinic showed that the transfer of nitric acid synthase gene to vascular grafts could reduce intima hyperplasia in human vein and arterial tissue in culture.

Although these examples show how gene therapy could potentially be applied to cardiovascular disease, overall clinical studies demonstrating improved myocardial function after a genetic intervention are lacking. The study by Abunasra and colleagues ${ }^{11}$ published in this issue of the Journal examined donor rat hearts perfused with a hypothermic solution containing adenoviral vector carrying the genes for endothelial nitric oxide synthase, manganese superoxide dismutase, or both. Four days later, transplanted hearts were collected, isolated in the Langendorff preparation, and subjected to 6 hours of ischemia followed by 1 hour of reperfusion. Both endothelial nitric oxide synthase and manganese superoxide dismutase expressions were increased by gene transfer. Function after ischemia-reperfusion was increased with transfection of either gene, but not the combination. This study was well performed, but similar findings have been demonstrated with nitric oxide donors such as L-arginine and nitroglycerin or various forms of superoxide dismutase. The new aspect to this study is that the substances were delivered by gene therapy. It has been estimated that there are about 10,000 articles dealing with myocardial protection with additives to cardioplegic solutions, blood versus crystalloid cardioplegia, warm versus cold versus tepid cardioplegia, complement antibodies, neutrophil filters, and so on. Does anyone currently add anything but blood to a cardioplegic solution except for research purposes? There have been almost no studies to demonstrate a clinical benefit of adding a substance to the cardioplegic solution, despite a multitude of articles report- 
ing a significant benefit in animals with lidocaine, propranolol, adenosine, and many other compounds. Since additives to cardioplegic solutions add little or no clinical benefit to the health of patients, would we expect the same substances delivered by gene therapy to do anything different? The article in this issue deals with a rat model of cardiac transplantation. Will more hearts become available if we can increase the donor pool by increasing the amount of time allowed to transport a donor heart? With so few donor hearts available anyway, I suspect that the answer is no. This is not to say that research directed toward improving tolerance of myocardium to an ischemic insult is not valuable work. However, it remains to be seen what gene therapy will actually do to expand therapeutic options and improve the health of patients.

There are several considerations that need to be addressed before gene therapy or any new therapy is subjected to clinical trials or use of the new therapy becomes widespread. ${ }^{12,13}$ Investigators need to ensure adequate protection of human subjects in clinical research in general, and in gene therapy trials specifically they need to ensure ethical conduct of research. First, researchers need to be certain that subjects fully understand all the potential risks of a clinical trial. Patients who do not understand the potential risks of a trial cannot be said to have chosen freely to face those risks. Second, the Food and Drug Administration has identified cases in which researchers failed to disqualify subjects who did not meet the criteria for a gene therapy study, failed to report adverse events as required, failed to ensure that a protocol was followed, and failed to ensure that study staff had adequate training. This procedure needs to be closely monitored and maintained. Third, institutional review boards, the key element of the system to protect research subjects, have excessive workloads and inadequate resources. Thus adequate evaluation of protocols may not have occurred before the initiation of the trial. Finally, conflicts of interest and ethical dilemmas arise because academic researchers serve as both investigators and sponsors or patent holders of products. The researcher's selfinterest may influence his or her scientific judgment.

In addition to the protection of study subjects, studies of gene therapy should consider the following issues ${ }^{12,13}$ :

- The placebo effect is extremely powerful in patients with end-stage cardiac disease.

- Randomized clinical trials are powerful tools for eliminating confounding variables but cannot reduce investigator bias or the placebo effect.

- Patient and investigator blinding would eliminate the placebo effect and investigator bias, effectively reduce crossover (which dilutes treatment effect), and minimize differences in other aspects of medical care.

- Blinding of studies involving patients with end-stage cardiac disease may be perceived as unethical. How- ever, this caveat may be overcome by thoughtful study design. It is probably more ethical to enroll a few patients in a well-designed and adequately powered placebo-controlled study than to treat hundreds of patients with a treatment that is later shown to be ineffective.

- No-option patients (those with end-stage coronary artery disease or heart failure) may also exhibit a "physiologic placebo effect" whereby ineffective treatment induces symptomatic relief paralleled by improved exercise tolerance, improved cardiac conditioning, and potential improved collateralization or myocardial contractile function.

There have been several recent cases in which investigators did not follow the guidelines, and they have suffered the consequences. Before further clinical work is initiated in the area of gene therapy, we need to standardize the evaluation of efficacy and ensure adequate protection of subjects. Gene therapy offers a tremendous opportunity to improve the care of critically ill patients with heart disease. However, its exact role remains to be seen. The overzealous enthusiasm of the investigators should not get in the way of the optimal care of the patients. Strict guidelines need to be followed with gene therapy trials as with most other clinical trials. The efficacy of a treatment needs to be verified before gene therapy is applied. If a protein is not effective for the treatment of a cardiac illness, the administration of an adenoviral vector is not likely to provide much benefit to the patient.

\section{References}

1. Sellke FW, Simons M. Angiogenesis in cardiovascular disease: current status and therapeutic potential. Drugs. 1999;58:391-6.

2. Ruel M, Laham RJ, Parker JA, Post MJ, Ware JA, Simons M, et al. Long-term effects of surgical angiogenic therapy with fibroblast growth factor 2 protein. J Thorac Cardiovasc Surg. 2002;124:2834.

3. Rosengart TK, Lee LY, Patel SR, Sanborn TA, Parikh M, Bergman $\mathrm{GW}$, et al. Angiogenesis gene therapy: phase 1 assessment of direct intramyocardial administration of an adenovirus vector expressing VEGF121 cDNA to individuals with clinically significant severe coronary artery disease. Circulation. 1999;100:468-74.

4. Baumgartner I, Pieczek A, Manor O, Blair R, Kearney M, Walsh K, et al. Constitutive expression of phVEGF165 after intramuscular gene transfer promotes collateral vessel development in patients with critical limb ischemia. Circulation. 1998;97:1114-23.

5. Logeart D, Hatem SN, Rucker-Martin C, Chossat N, Nevo N, Haddada $\mathrm{H}$, et al. Highly efficient adenovirus-mediated gene transfer to cardiac myocytes after single-pass coronary delivery. Hum Gene Ther. 2002;11:1015-22.

6. Davidson MJ, Jones JM, Emani SM, Wilson KH, Jaggers J, Koch WJ, et al. Cardiac gene delivery with cardiopulmonary bypass. Circulation. 2001;104:131-3.

7. Bridges CR, Burkman JM, Malekan R, Konig SM, Chen H, Yarnall $\mathrm{CB}$, et al. Global cardiac-specific transgene expression using cardiopulmonary bypass with cardiac isolation. Ann Thorac Surg. 2002;73: 1939-46.

8. Wang J, Ma Y, Knechtle SJ. Adenovirus-mediated gene transfer into 
rat cardiac allografts: comparison of direct injection and perfusion. Transplantation. 1996;61:1726-9.

9. Zhu HL, Stewart AS, Taylor MD, Vijayasarathy C, Gardner TJ, Sweeney HL. Blocking free radical production via adenoviral gene transfer decreases cardiac ischemia-reperfusion injury. Mol Ther. 2000;2:470-5.

10. Cable DG, Caccitolo JA, Caplice N, O'Brien T, Simari RD, Daly RC, et al. The role of gene therapy for intimal hyperplasia of bypass grafts. Circulation. 1999;100(19 Suppl):II392-6.
11. Abunasra HJ, Smolenski RT, Yap J, Sheppard M, O'Brien T, Yacoub $\mathrm{MH}$. Multigene adenoviral therapy for the attenuation of ischemiareperfusion injury after preservation for cardiac transplantation. J Thorac Cardiovasc Surg. 2003;125:998-1006

12. Laham RJ, Simons M, Sellke FW. Gene transfer for angiogenesis in coronary artery disease. Аппи Rev Med. 2001;52:485-502.

13. Shalala D. Protecting research subjects-what must be done. $N$ Engl J Med. 2000;343:808-10.

\section{UN THE MOVE?}

Don't miss a single issue of the journal! To ensure prompt service when you change your address, please photocopy and complete the form below.

Please send your change of address notification at least six weeks before your move to ensure continued service. We regret we cannot guarantee replacement of issues missed due to late notification.

\section{JOURNAL TITLE:}

Fill in the title of the journal here.

OLD ADDRESS:

Affix the address label from a recent issue of the journal here.

\section{NEW ADDRESS:}

Clearly print your new address here.

Name

Address

City/State/ZIP
COPY AND MAIL THIS FORM TO:

Mosby

Subscription Customer Service

6277 Sea Harbor Dr

Orlando, FL 32887
OR FAX TO:

407-363-9661

N/M Mosby
OR PHONE:

800-654-2452

Outside the U.S., call

407-345-4000 